\title{
Postharvest Biology and Technology
}

Volume 118, August 2016, Pages 134-140

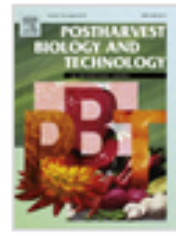

\section{Combined effect of antimicrobial coatings, gamma radiation and negative air ionization with ozone on Listeria innocua, Escherichia coli and mesophilic bacteria on ready-to-eat cauliflower florets}

\author{
Afia Boumail, Stephane Salmieri, Monique Lacroix $\mathbf{a}$ \\ † Show more
}

https://doi.org/10.1016/j.postharvbio.2016.04.005

Get rights and content

Highlights

- The antimicrobial coating induced inhibition of the bacterial growth during storage.

- Negative air ionization + ozone treatments can be used to reduce bacterial growth.

- Coating combined with gamma radiation inhibited the growth of Listeria and $E$. coli.

- An additive effect was observed between the antimicrobial coating and NAI/ozone.

- A synergic effect was observed between the antimicrobial coating and gamma radiation. 